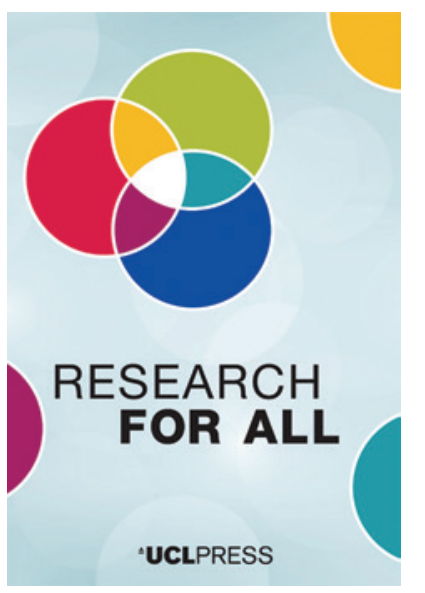

${ }^{ \pm}$CLPRESS

\section{RESEARCH FOR ALL}

The open-access journal for public engagement with research

ISSN 2399-8121 (Online)

Journal homepage:

https://www.uclpress.co.uk/pages/research-for-all

\title{
Enabling participation of Black and Minority Ethnic (BME) and seldom-heard communities in health research: A case study from the SCAMP adolescent cohort study
}

Jane Bruton (D) and Kathryn Jones (D)

Rosemary H. Jenkins (D, Bethan Davies (D, Helen Ward (iD and Mireille B. Toledano iD

\section{How to cite this article}

Bruton, J., Jones, K., Jenkins, R.H., Davies, B., Ward, H. and Toledano, M.B. (2020) 'Enabling participation of Black and Minority Ethnic (BME) and seldom-heard communities in health research: A case study from the SCAMP adolescent cohort study'. Research for All, 4 (2), 207-19. Online. https://doi.org/10.14324/RFA.04.2.06

Submission date: 10 May 2019

Acceptance date: 5 May 2020

Publication date: 22 September 2020

\section{Peer review}

This article has been peer-reviewed through the journal's standard double-blind peer review, where both the reviewers and authors are anonymized during review.

\section{Copyright}

(C) 2020 Bruton, Jones, Jenkins, Davies, Ward and Toledano. This is an open-access article distributed under the terms of the Creative Commons Attribution Licence (CC BY) 4.0 https:// creativecommons.org/licenses/by/4.0/, which permits unrestricted use, distribution and reproduction in any medium, provided the original author and source are credited.

\section{Open access}

Research for All is a peer-reviewed open-access journal. 


\title{
Enabling participation of Black and Minority Ethnic (BME) and seldom-heard communities in health research: A case study from the SCAMP adolescent cohort study
}

\author{
Jane Bruton* and Kathryn Jones - Imperial College London, UK
}

Rosemary H. Jenkins, Bethan Davies, Helen Ward and

Mireille B. Toledano - Imperial College London, UK

\begin{abstract}
Our inquiry investigated the barriers to, and facilitators for, the involvement of Black and Minority Ethnic (BME) and 'seldom-heard' communities, in a study researching the impact of mobile phone and wireless device usage on adolescents' cognition, behaviour and mental health. The aim was to co-produce solutions to increase participation, and we used focus groups, telephone interviews, a community event and a public and patient involvement (PPI) café to conduct the inquiry. Five themes emerged from the data: two enablers - the value and benefits of research; and three barriers - concerns about research and about communication, and practical constraints. A central cross-cutting theme, the concept of trust, was evident from the data, and extended across all themes, including across the solutions to nonparticipation. When the data collection and analysis were completed, we ran a symposium for researchers and members of the public to share our findings and to co-produce solutions. The symposium generated ideas about improving participation, including tailoring participant information, engaging with local advocates and involving people in research design and delivery.
\end{abstract}

Keywords: seldom heard, BME, research participation, co-production, PPI, parental consent

\section{Key messages}

- Parental consent rates to research that links their child's study responses to routine health data are notably lower within BME groups and among those of medium or low socio-economic status.

- Consent may be motivated by curiosity, altruism, an opportunity for learning, or by a personal stake in the focus of study.

- Concerns about data security and privacy, and distrust of government research, may be overcome by involving trusted advocates, such as local religious or community leaders, GPs or head teachers.

\section{Introduction}

There is evidence and concern that people from Black and Minority Ethnic (BME) communities are proportionately under-represented in health and social research in the US and the UK, compared with the majority White populations (Wendler et al., 2006; 
Sheikh et al., 2009; Smart and Harrison, 2017). From the cited literature, this does not appear to have changed over time. BME adolescents, like their adult counterparts, are also under-represented in health and social research (Kearney et al., 1983; Unger et al., 2004). While acknowledging that considerable heterogeneity exists within BME populations, this lack of inclusion of specific groups compromises our understanding of the issues for population health and well-being, and the potential differences between groups, which in turn impedes the generalizability of the research and its translation into the development of appropriate services (Gill et al., 2013; George et al., 2014). Rugkåsa and Canvin (2011) go further, arguing that inclusion is a matter of social justice, without which inequality in service provision and the power structures that lead to marginalization are perpetuated.

Often, BME groups are characterized as the 'hard to reach' or 'seldom heard', which might imply that the barriers to participation are inherent within the BME community - an unwillingness to engage or share perspectives - rather than described as 'easy to ignore', which puts the spotlight on the researchers and their approach to recruitment, and challenges their assumptions (Wendler et al., 2006; Sheikh et al., 2009; Vickers et al., 2012). Sheikh et al. (2009) describe the positive impact of legislation in the US, through the National Institutes of Health, that requires inclusion of people from BME groups in health research. He found that US researchers were more positive than UK researchers about broadening research participation. They had developed creative strategies to recruitment - for example: community leaders hired as paid study personnel; cooperation with other research teams to recruit subjects with appropriate racial or ethnic characteristics; and working with potential participants in their 'territory' by going to homes and community centres, hosting events and setting up study clinics in accessible places. They also had structures and funding to support these initiatives, which resulted in increased confidence, experience and expertise in increasing participation, albeit this change of approach took time.

It is commonly accepted that people often have more than one identity that they are comfortable with and which vary according to different situations (Vickers et al., 2012). For example, Hussain-Gambles et al. (2004) found in a study with South Asian participants that social class affected inclusiveness more than ethnicity.

Intersectionality theory provides an additional lens on profiling, or the axis on which populations may be categorized or defined. Originating in Black feminist scholarship, the theory acknowledges 'intersections' of social identity, for example, race, class and gender (Bauer, 2014; Green et al., 2017). Green et al. (2017: 216) argue that intersectionality encourages researchers to consider how social determinants such as racism, sexism and classism form 'interlocking systems of oppression' that shape people's lives as a consequence of their multidimensional social identities and result in the production of health inequalities.

Finally, in relation to young people from BME communities, the underrepresentation is primarily linked to the type of parental consent required for different research studies (Kearney et al., 1983; Thompson, 1984; Dent et al., 1993; Anderman et al., 1995; Unger et al., 2004). School-based research is considered an effective and inclusive method of conducting research among young people, where school enrolment is compulsory (Testa and Coleman, 2006). However, a number of schoolbased studies looking at active versus passive or implied parental consent show that where there is a requirement for active parental consent, for example, when sensitive issues such as sexual health are being researched, or when linkage to routine health data held by NHS Digital is required, this results in proportionately fewer participants from BME communities (Kearney et al., 1983; Dent et al., 1993; Anderman et al., 1995; 
Testa and Coleman, 2006; Powell and Smith, 2009). Those not participating are often the most vulnerable or at risk. Any difference to the risk profiles of people not included in studies compared to those included leads to skewed findings, which impacts on the usefulness of the research (Unger et al., 2004; Rojas et al., 2008). With the requirement for consent, the same issues of 'easy to ignore' apply.

\section{The project}

Our inquiry was a collaborative project between the Patient Experience Research Centre (PERC) and the Study of Cognition, Adolescents and Mobile Phones (SCAMP), both at Imperial College London, to investigate the barriers to, and facilitators for, the involvement of seldom-heard groups in the SCAMP study. SCAMP is researching the impact of mobile phone and wireless device usage on adolescents' cognition, behaviour and mental health. SCAMP is the largest cohort study in the world to date to address this research question. The study adopted an opt-out recruitment approach to achieve optimum diversity, reduce selection bias, improve feasibility of a school-based computerized assessment and ensure cost-effectiveness (Toledano et al., 2019). However, parental consent was required under data protection law (the Data Protection Act 1998 - see UK Parliament (2005)), in order to link the study data with routine health, education and mobile phone operator records, and for personal and home environmental exposure monitoring that required researchers to enter and install equipment in adolescents' homes. In the early stages of the SCAMP study, focus groups with parents, teachers and children were held to co-produce research materials, including the consent form for linkage to routine records.

Analysis of the baseline consent for routine records linkage revealed inequalities in the consented group compared to the rest of the cohort. For example, the SCAMP study team received consent from 19.2 per cent of White students, 12.2 per cent of students with mixed ethnicity, 11.4 per cent of Asian students and 5.9 per cent of Black students (see Toledano et al. (2019) for details on the full SCAMP cohort). The study team also examined rates of consent by socio-economic class (using statistics from 2017) and noted differences: 18.9 per cent of students with high socio-economic status, 13.4 per cent of students with medium socio-economic status and 7.4 per cent of students with low socio-economic status. Based on these findings, our collaborative project successfully applied for funding from an Impact Acceleration Account (IAA) award, run by the Economic and Social Research Council, to explore the barriers and facilitators to participation in research from seldom-heard communities. The terms of the award were to promote knowledge exchange and engagement with an aim of accelerating the impact of research, and on this basis the team was not required to seek ethical approval for our inquiry. The PERC and SCAMP teams are committed to supporting co-creation and collaboration with the public and patients at each stage of the research process.

The aims of this piece of work were to identify the barriers to study participation, specifically, the provision of consent for data linkage in seldom-heard groups, and to initiate a dialogue on how to gain trust with seldom-heard individuals. The Social Care Institute for Excellence (Robson et al., 2008) explain that the term 'seldom heard' implies the responsibility that a service provider holds to ensure that all people who can potentially access services should have their voices heard, influencing service and policy development, including research. We wanted to translate the knowledge we gleaned into practice, both within the SCAMP study and in the wider research community within our academic institution. We planned to do this through a series of 
engagements with seldom-heard groups and individuals, and by co-producing specific actionable solutions that could be shared by collaborating more widely with the research community through a symposium. We hoped that by sharing any co-produced findings in this way, we could discuss whether they resonated with other researchers' experience and initiate further discussion of their relevance within the research community. Finally, we aimed to co-produce actions that provide an opportunity to influence other researchers' thinking to improve the inclusion of seldom-heard groups in future research, in terms of both involvement and participation.

\section{Methods}

We conducted our inquiry using focus groups, telephone interviews, a community event and a public and patient involvement (PPI) café at a science festival. Two of the focus groups were held in community centres to attract those from seldomheard groups. Despite advertising the first focus group with posters in local shops, schools and in the integrated community/medical centre, and an advertisement on the council's online 'what's on' calendar, no one attended. This prompted us to change our recruitment strategy and harness established engagement links we had with a local ethnically diverse community via a university-funded community engagement officer. This resulted in good attendance at the second focus group, primarily from people of BME backgrounds. Some of the attendees came through snowballing, that is, bringing a friend along who had not heard about the event. With hindsight, involving one or two local community leaders in the setting up of the first focus group, and in the design and distribution of recruitment materials, might have led to greater participation.

Telephone interviews were conducted with parents already involved in the SCAMP study to get a perspective on why they chose to participate. We attended a community event held by the local professional football team in the heart of an ethnically diverse area, which included a public health initiative organized by our university community engagement team. Our stall had an eye-catching 'wheel of fortune' game about mobile phone use, which provided opportunities to engage parents and children in a dialogue about phone usage, research and consent. Finally, the PPI café took advantage of the large footfall at the science festival and attracted a mixed group of people interested in PPI in research. These engagement opportunities enabled us to access a wider group of people who were unable to attend a focus group. The final focus group was held at a central London location, as this was more convenient for the parents who were attending from various parts of the city.

We explained the nature of our inquiry to all prospective participants, and gained their verbal consent to take part. We used a systematic approach to sift, chart and organize the data according to key issues and themes (Ritchie and Spencer, 1994). We considered this approach appropriate to deal with the volume, wealth and context of our data, and it allowed simultaneous and cross-method analysis to address our inquiry (Stake, 1995).

While we did not commence this project with an underpinning theoretical framework, it was clear as we collected data and read the relevant literature that although we were looking specifically at the barriers and facilitators for BME, our participants were ethnically diverse, with multiple identities such as gender, class, sexuality and ability. This led us to consider and adopt an intersectionality framework within the iterative analysis of our data to further enhance their meaning. Clarke and McCall (2013) point out that their research starts with the question concerning inequality, with intersectionality being a useful tool later in the process for generating new social explanations. 
When the data collection and analysis were completed, we ran a symposium for researchers and members of the public to share our findings and to co-produce solutions.

\section{Results}

We conducted our inquiry in London between March and May 2018. A total of 15 participants attended the two focus groups: 8 parents of SCAMP participants and 7 members of the public who were also parents. The demographics of Group One were as follows: 1 male, 10 females, of whom 4 were Black African, 2 White British, 1 Black British, 1 British Asian, 1 Korean American, 1 White European and 1 White Russian. Group Two attendees were all parents of SCAMP participants; the demographics were as follows: 2 males and 2 females, of whom 3 were White Other and 1 was White British. All participants had children of UK school age. Group One was hugely diverse across different ethnicities, although more congruent regarding gender and parenthood. We did not collect data on participants' socio-economic status, but observed that local participants were from a recognized deprived area of London compared with those who had travelled to our focus groups from other parts of London.

In addition, we conducted six telephone interviews with parents of SCAMP participants, all of whom were female and working in professional roles, including research. They were unable to attend a focus group but were interested in contributing to the project. We also discussed the issues with around 20 residents at a local football club community day and 32 participants at a PPI café during our university science festival. Both latter groups were of mixed age, gender and ethnicity.

Five themes emerged from the data: two enablers - the value and benefits of research; and three barriers - concerns about research and about communication, and practical constraints. A central cross-cutting theme, the concept of trust, emerged from the data and extended across all themes, including across the solutions to nonparticipation (see Figure 1).

We explore here each theme in detail. Our discussions revealed that, overall, the participants would be more likely to let their children take part in research if they (the parents) believed in the value of research and felt it was of benefit to others. This finding was consistent across all types of contact and across all ethnic groups. For example, our participants discussed that they would be more likely to consent for their children to take part in research if they (the parents) or their family had an interest in the subject, with one woman describing a family member with a chronic illness, and explaining that if research focused on that condition, she would encourage her child to take part. Others discussed the altruistic aspects of participation, for example, contributing to knowledge and finding out the answers, with one woman describing her family as curious and interested in science and, therefore, keen to contribute to society and to make a difference for others. Most participants expressed the benefit they perceived in their children taking part in research, learning more about the topic, science, the research process and how data are gathered, and giving them a better understanding of consent issues through seeing how scientists (and doctors) take consent seriously. One participant thought that participation in research was educational for both children and parents. In our specific case, some of the discussions focused on the participants' perceived need for information about the research topic - mobile phone use - both to understand any health and well-being impacts, but also as a way of asserting influence on their children's mobile phone usage and behaviours. This may have motivated them to consent for their children to take part. 
Figure 1: Summary of participants, findings and overall results

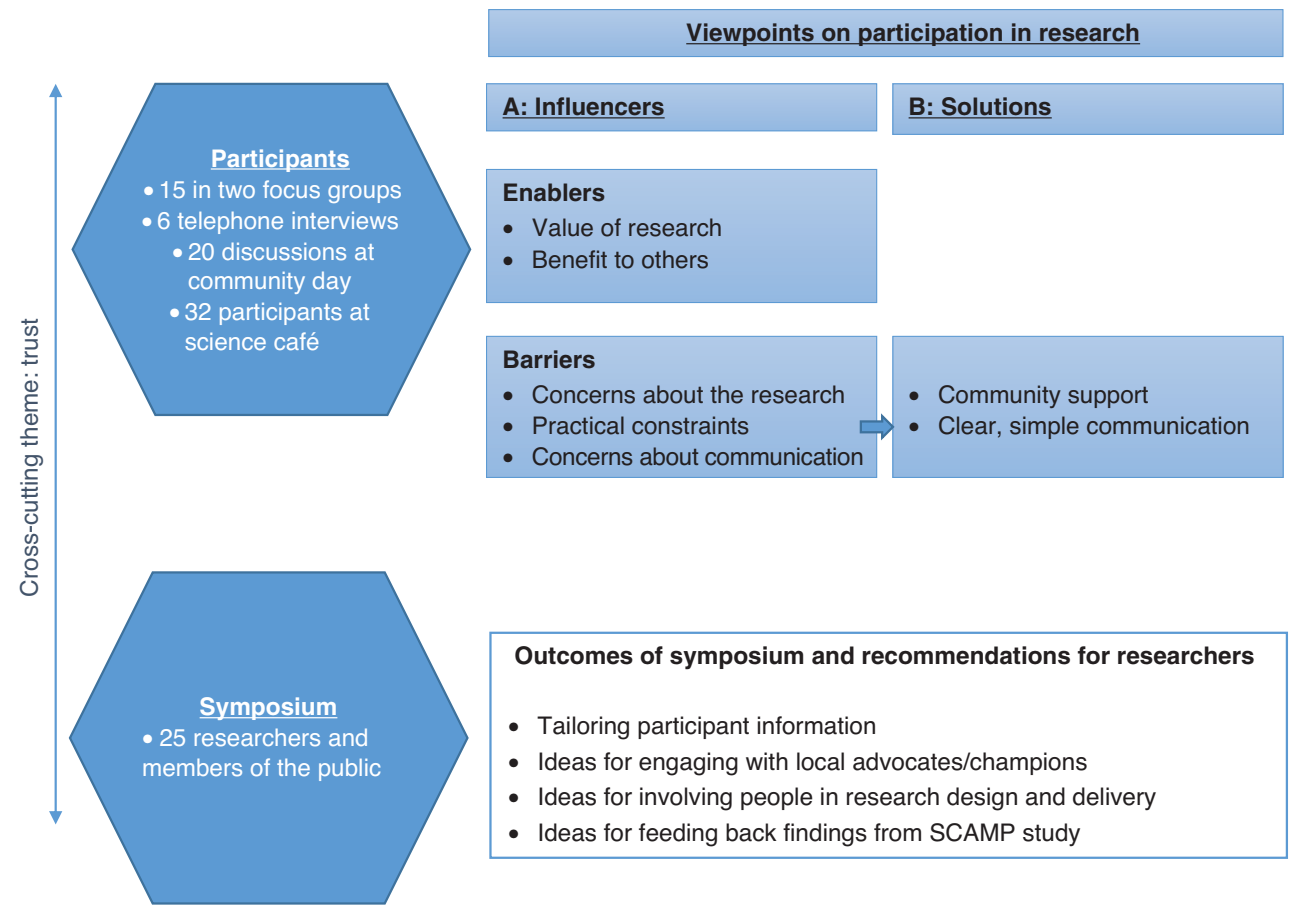

First, our discussions revealed that, overall, the participants would be less likely to let their children take part if they had concerns about the research, such as the level of potential harm or risk to the child; suspicion or lack of trust in the motivation of the researchers; the security of data sharing and risks to privacy; and breaches of confidentiality. Security of data sharing was a big issue for most people to whom we spoke. Some expressed concerns about the risk of data being lost or even sold, or being used for other purposes. This was of concern to them as the research involved their children. The participants would want to know who was funding the research to be able to make an informed decision about whether the data would be properly protected. One participant chose to contact SCAMP to get clarity on these issues before she signed the consent form. While these findings were remarkably consistent across all types of contact, one BME focus group participant expressed particularly strong views about suspicion and lack of trust in any government-related research. Her worries centred on the motivation for the research and the potential misuse of data; she explained that she would actively discourage her child from taking part in this type of research. The concept that some communities tended to distrust the 'establishment' also featured in our final focus group. Second, the participants identified practical constraints as a barrier to participation, such as lack of time, apathy, and worries about the design of the study or the length or complexity of the consent documentation. For example, participants remarked on the volume of memos, letters and information that come from schools on everyday matters, which then, because of busy lives, get left unread. Other parents of SCAMP participants felt that the consent form was too long and quite complex. Finally, they would be less likely to participate if they had concerns about the communication related to the study: whether there was either too much information about it or too little, or how and in what form information was communicated to them or by whom, and the impact of any language barriers. While these views were broadly consistent across the types of contact, participants from the 
two separate focus groups articulated some variance in relation to whom they would trust in a communication role. Interestingly, the BME participants said that they would trust information from community workers, local leaders and health workers, whereas the White participants identified schoolteachers, and particularly the head teacher, as most trusted.

As we were interested in co-producing specific, actionable solutions that might increase participation in research by people from seldom-heard groups, we asked participants (from the focus groups, interviews and community events) what actions might be taken to address the barriers that they had identified to taking part in research. First, they felt these barriers could be overcome by approaching people using community support, such as trusted advocates from local religious groups, the local GP, and strong school support, particularly from head teachers who are respected. It was reported by most of the parents of the SCAMP participants that financial incentives did not act as a motivator, apart from one child who was keen to earn the monetary vouchers available in this study. Some participants suggested that it was important to engage with the children first - 'win the kids first' - which could influence the parents to consent. In the interest of trust between child and parent, most participants were clear that they would not consent to something their child did not want to do. In addition, enthusiastic children were thought to help recruitment through their friend networks. Most participants thought that the reputation of the research organization was important in engendering trust.

The second key theme for solutions was clear, simple communication about any study. This included how it was advertised and how people were recruited, what involvement participants had in the design of the research, as well as understanding how to access study findings, and having regular contact with the researcher(s). One participant suggested that parents could help to write research information to make it simple and clear, and suggested that participant testimonials about the research might assist recruitment. Several participants addressed the problems of long consent forms, and one suggestion was to follow the example of information leaflets supplied with common medications, such as paracetamol, where key messages are highlighted as essential to read. Most participants thought that researchers should be readily accessible and, where possible, become known and embedded within the seldomheard communities. Several participants said that an important incentive for them would be assurance that they would receive regular feedback from the study and early sight of the final findings of the research.

Following the data collection and analysis of our findings, as described above, we attracted around 25 researchers and members of the public to the planned symposium. This event generated a lot of ideas about how to learn from each other to improve public and patient involvement in research: for example, tailoring participant information for different community groups, providing information in Easy Read and in multiple languages, and giving thought to how people in general access information. The symposium also generated ideas about the impact of the findings for SCAMP, including how to engage with local advocates and champions, how to involve people in the design and delivery of the research or in design of research materials, the value of providing information in an easy-to-understand format, and what types of incentives might work. Feedback from the symposium participants showed that the findings resonated with their own experience, and that they valued the diversity of the attendees and the small discussion group format, which they felt facilitated sharing of ideas and solutions. To continue to inform the research community, we plan to publish our findings in a local blog. 


\section{Discussion}

As shown in the literature, BME communities are under-represented within health and social research (Gill et al., 2013; Vickers et al., 2012; Smart and Harrison, 2017). Most researchers are keen to increase and broaden participation in research (Sheikh et al., 2009). To this end, the SCAMP team chose a schools-based and opt-out (passive/ implied parental consent) method of recruitment, which is accepted as the preferred and most effective approach to recruit young people into research (Esbensen et al., 1996; Testa and Coleman, 2006; Powell and Smith, 2009). However, as with other studies, the requirement for parental consent, in this case for the data sharing and personal and home exposure monitoring parts of the study, resulted in an underrepresentation of BME adolescents, despite the research taking place in ethnically diverse schools (Kearney et al., 1983; Unger et al., 2004; Rojas et al., 2008). We sought to investigate with parents, and members of the public, the barriers, facilitators and possible solutions to recruiting adolescents from BME communities.

Initially, the biggest challenge we faced was recruiting BME members of the public to our focus groups, which was our chosen method of inquiry. The fact that no one attended the first focus group highlighted the need to review our methods of communication and recruitment. Key to this was using the established links made by the university-funded community engagement officer, who is embedded and trusted within the local community. Alongside this, we decided not to rely solely on focus groups as the method of inquiry, and we extended our reach through participating in a community-arranged football event; contacting all, and interviewing some, parents of SCAMP participants; and finally, engaging with people who were interested in patient and public involvement in research through novel café-style discussions. Being successful with recruitment to the second focus group of participants, and extending our reach, as described, concurred with the results of other studies that rather than people from BME communities being unwilling to participate in the focus group, it was more the method of recruitment that was a barrier (Wendler et al., 2006; Gill et al., 2013). Being willing and able to try different and more creative approaches to communication and recruitment, such as use of incentives, cultural congruence of researchers, and direct communication with researchers, have been shown to increase participation from BME communities (Thompson, 1984; Sheikh et al., 2009). Some of these solutions to increase participation were raised by participants in our study, particularly direct communication with the researchers within the community. Some participants raised the use of incentives as a potential solution. However, although the SCAMP study offered incentives to the adolescents, parents of SCAMP participants reported that this had made little difference to their children's willingness to participate. Also, in reference to the impact of participants' personal attitudes to participation in research, it might be that a combination of approaches - for example, direct communication with parents as well as incentives for children and for families - would yield improved participation rates, as seen by Thompson (1984).

The facilitators to participation identified by the participants were grouped under two themes: value of research and benefit to others. We found that in our inquiry, participants were very interested in the research topic - use of mobile phones - and considered it important to develop an evidence base, given that mobile phone usage was often a source of conflict in families. Research in this area was seen as relevant to both the families and the community. Several studies highlight the importance that potential participants place on research that is seen as helping the family and/or the community, and contributing to the development of knowledge, which engenders a 
sense of altruism and willingness to contribute (Corbie-Smith et al., 1999; Smith et al., 2007; Woodall et al., 2010; George et al., 2014). Trust in researchers and the reputation of the research organization was deemed by the participants as important for promoting participation. Several studies concur, citing cultural congruence, embeddedness in the community and/or links with respected local leaders or health professionals as promoting trust and participation (Smith et al., 2007; Rooney et al., 2011; Gill et al., 2013; George et al., 2014). However, Rugkåsa and Canvin (2011) point out that when researchers engage with gatekeepers, such as community advocates, they need to be aware of the potential for those gatekeepers to either constrain or facilitate participation. The reputation of our research organization was known among the community through an active local engagement programme. Finally, some participants spoke of the educational and personal value of children being involved in research, particularly in understanding the concept of consent. This is supported by research that highlights the benefits of young people's participation in research, giving them more insight into their own behaviours and enhancing their decision-making capacity, through the process of informed consent (Sanci et al., 2004; Powell and Smith, 2009).

The barriers to participation identified by the participants were grouped under three themes: concerns, constraints and communication. The major concern cited in the literature is mistrust of research and researchers, particularly around issues of confidentiality and fear regarding legal status (Corbie-Smith et al., 1999; Smith et al., 2007; Woodall et al., 2010; George et al., 2014). Some of these fears were raised by participants in our study in relation to consenting for data linkage of confidential documents for their children. However, for most, this concern would be allayed if there was direct contact with researchers, and support for the research by trusted community advocates, such as religious leaders and head teachers. Of note, the timing of our data collection coincided with multiple media coverage focused on data security and leakage of data from social media sites. Since our data were collected, much has been reported in the British press about surveillance of migrants, in particular, recognition of a 'hostile environment' policy resulting from a set of legislative and administrative changes aiming to reduce overall net immigration. Variously, the impact of the policy on individuals and communities has been reported, including struggles to remain in the country and access public services, with compelling reports of the impact on the Windrush generation and on survivors of the Grenfell Tower fire (the building was situated in our study's community) (Hiam, 2017; McKee, 2018; Hiam et al., 2018). These policy and legislative changes should be acknowledged when reflecting on the themes of trust and mistrust raised by our participants. Our participants frequently described constraints, including competing demands on their time, and these were confirmed in the literature (George et al., 2014). Direct communication of researchers with potential participants addresses the third theme, poor communication, which was described by the participants as involving either too much information, which puts people off reading it, or not enough information and information often being written in inaccessible language. They suggested clear simple information about the study, preferably delivered face to face by researchers, and recruiting through snowballing and local leaders. The complexity of the consent form was highlighted as a further barrier to participation in our study. Ethics committees often work to a standardized framework for consent forms and participant information leaflets. A more flexible approach to approving shorter, more concise non-standard study documentation is recognized by several authors as beneficial to the recruitment of participants (McKeown et al., 2010; Gale et al., 2017). Howard et al. (2009) suggest that involvement of key stakeholders in the design of research studies, including the study information, may 
prove to be vital in improving recruitment and participation. This was done from the initial stages of design of the SCAMP study, and it may have helped inclusiveness, but it was still insufficient to achieve equal participation by seldom-heard groups; other strategies clearly need to be employed alongside this.

The outcomes of our inquiry, described above, detail the methods needed to enhance inclusion in research, and they are applicable to all potential participants. However, we recognize that some people are differentially disadvantaged for reasons such as racism, poverty or social class; because they come from stigmatized groups such as sex workers, the traveller population or prisoners; or because they are living with a disability. Our findings, although not unique, are strengthened through the process of co-creation with people from seldom-heard groups and researchers. The implications for research practice reaching out to the 'seldom heard' or 'easy to ignore' are for researchers to be aware of the needs of the potential participants, to involve stakeholders in the research process, and to have sufficient time and resources within the study to maintain a flexible approach (Beadle-Brown et al., 2012). Our recommendations for other researchers are summarized in Figure 1.

Our small collaborative study was funded by an award that sought to promote knowledge exchange and engagement to accelerate the impact of research. We aimed to co-create and collaborate throughout our inquiry to co-produce solutions that would help shape researchers' understanding of the barriers and facilitators to participation of people from BME communities in research, and how to improve participation rates. Our inquiry provided multiple opportunities for co-creation and co-production with the participants, as well as a range of platforms for parents of SCAMP participants to contribute to the emerging knowledge base. Interestingly, through participating in this inquiry, we experienced the difficulty of engaging participants. We acknowledged that as individual researchers we were not embedded within the local communities that we were attempting to engage, which initially resulted in no response to the first focus group. However, by adapting our research approach, and by working with embedded and trusted community champions from our university, we overcame some of these difficulties and were able to listen to, engage and collaborate with people from seldom-heard groups. Finally, using a collaborative approach to the symposium proved to be an effective tool that gave us access to other researchers and members of the public who we would not normally meet. We intend to build on the relationships made within the symposium to further our inquiry into improving participation of people from BME groups and potentially other seldom-heard groups.

\section{Acknowledgements}

We acknowledge all those who took part in the focus groups, those who worked at the community centres in which they took place, and Priya Patel for her help in engaging the community; the SCAMP study team; SCAMP schools, participants and their parents; the Patient Experience Research Centre team; and all the researchers who attended the symposium.

\section{Funding statement}

This work was funded by Imperial College's Economic and Social Research Council Impact Acceleration Account. The SCAMP study is supported by the UK Department of Health and Social Care via the Research Initiative on Health and Mobile 
Telecommunications (RIHMT) (grant number: 091/0212), an independent programme of research that is jointly funded by the UK Health Departments, the Medical Research Council, the Health and Safety Executive and industry funders (Vodafone, Arqiva, Carphone Warehouse, BT, 3UK, Everything Everywhere EE (Orange and T-Mobile) and Telefonica Europe plc (O2)). The RIHMT is managed by the UK Department of Health and Social Care's Policy Research Programme. Some SCAMP study enhancements are supported by the National Institute for Health Research Health Protection Research Unit (NIHR HPRU) in Health Impact of Environmental Hazards at King's College and Imperial College London in partnership with Public Health England (PHE) (grant number: HPRU-2012-10141), and also supported, in part, by funds from the MRC-PHE Centre for Environment and Health (MR/L01341X/1). Helen Ward, Kathryn Jones, Jane Bruton and Bethan Davies are supported by NIHR Imperial Biomedical Research Centre. Helen Ward is also funded by a Collaborative Award in the Medical Humanities and Social Sciences from the Wellcome Trust. The views expressed in this publication are those of the authors and not necessarily those of the National Health Service, the NIHR, the Department of Health and Social Care or PHE.

\section{Notes on the contributors}

Jane Bruton and Kathryn Jones are the joint first authors of this article and are members of the Patient Experience Research Centre at Imperial College London.

Rosemary H. Jenkins was a member of the SCAMP team while undertaking the inquiry.

Bethan Davies was a member of the Patient Experience Research Centre at Imperial College London.

Helen Ward is Professor of Public Health and Director of the Patient Experience Research Centre at Imperial College London.

Mireille B. Toledano is Professor in Epidemiology at Imperial College London and Principal Investigator for the SCAMP study.

\section{References}

Anderman, C., Cheadle, A., Curry, S., Diehr, P., Shultz, L. and Wagner, E. (1995) 'Selection bias related to parental consent in school-based survey research'. Evaluation Review, 19 (6), 663-74. Online. https://doi.org/10.1177/0193841X9501900604

Bauer, G.R. (2014) 'Incorporating intersectionality theory into population health research methodology: Challenges and the potential to advance health equity'. Social Science and Medicine, 110, 10-17. Online. https://doi.org/10.1016/j.socscimed.2014.03.022

Beadle-Brown, J., Ryan, S., Windle, K., Holder, J., Turnpenny, A., Smith, N., Richardson, L. and Whelton, B. (2012) Engagement of People with Long-Term Conditions in Health and Social Care Research: Barriers and facilitators to capturing the views of seldom-heard populations. Canterbury: QORU.

Clarke, A.Y. and McCall, L. (2013) 'Intersectionality and social explanation in social science research'. Du Bois Review: Social Science Research on Race, 10 (2), 349-63. Online. https://doi.org/10.1017/ S1742058X13000325

Corbie-Smith, G., Thomas, S.B., Williams, M.V. and Moody-Ayers, S. (1999) 'Attitudes and beliefs of African Americans toward participation in medical research'. Journal of General Internal Medicine, 14, 537-46. Online. https://doi.org/10.1046/j.1525-1497.1999.07048.x 
Dent, C.W., Galaif, J., Sussman, S., Stacy, A., Burtun, D. and Flay, B.R. (1993) 'Demographic, psychosocial and behavioral differences in samples of actively and passively consented adolescents'. Addictive Behaviors, 18 (1), 51-6. Online. https://doi.org/10.1016/03064603(93)90008-W

Esbensen, F.-A., Piper Deschenes, E., Vogel, R.E., West, J., Arboit, K. and Harris, L. (1996) 'Active parental consent in school-based research: An examination of ethical and methodological issues'. Evaluation Review, 20 (6), 737-53. Online. https://doi.org/10.1177/0193841X9602000605

Gale, C., Hyde, M.J. and Modi, N. (2017) 'Research ethics committee decision-making in relation to an efficient neonatal trial'. Archives of Disease in Childhood - Fetal and Neonatal Edition, 102, F291-8. Online. https://doi.org/10.1136/archdischild-2016-310935

George, S., Duran, N. and Norris, K. (2014) 'A systematic review of barriers and facilitators to minority research participation among African Americans, Latinos, Asian Americans, and Pacific Islanders'. American Journal of Public Health, 104 (2), e16-31. Online. https://doi.org/10.2105/ AJPH.2013.301706

Gill, P.S., Plumridge, G., Khunti, K. and Greenfield, S. (2013) 'Under-representation of minority ethnic groups in cardiovascular research: A semi-structured interview study'. Family Practice, 30 (2), 233-41. Online. https://doi.org/10.1093/fampra/cms054

Green, M.A., Evans, C.R. and Subramanian, S.V. (2017) 'Can intersectionality theory enrich population health research?'. Social Science and Medicine, 178, 214-16. Online. https://doi.org/10.1016/j.socscimed.2017.02.029

Hiam, L. (2017) 'Grenfell survivors shouldn't be afraid to go to hospital'. British Medical Journal, 358, Article j3292, 1-2. Online. https://doi.org/10.1136/bmj.j3292

Hiam, L., Steele, S. and McKee, M. (2018) 'Creating a "hostile environment for migrants": The British government's use of health service data to restrict immigration is a very bad idea'. Health Economics, Policy and Law, 13 (2), 107-17. Online. https://doi.org/10.1017/S1744133117000251

Howard, L., De Salis, I., Tomlin, Z., Thornicroft, G. and Donovan, J. (2009) 'Why is recruitment to trials difficult? An investigation into recruitment difficulties in an RCT of supported employment in patients with severe mental illness'. Contemporary Clinical Trials, 30 (1), 40-6. Online. https://doi.org/10.1016/j.cct.2008.07.007

Hussain-Gambles, M., Leese, B., Atkin, K., Brown, J., Mason, S. and Tovey, P. (2004) 'Involving South Asian patients in clinical trials'. Health Technology Assessment, 8 (42). Online. https://doi.org/10.3310/hta8420

Kearney, K.A., Hopkins, R.H., Mauss, A.L. and Weisheit, R.A. (1983) 'Sample bias resulting from a requirement for written parental consent'. Public Opinion Quarterly, 47 (1), 96-102. Online. https://doi.org/10.1086/268769

McKee, M. (2018) 'Lessons from the Windrush generation'. British Medical Journal, 361, Article k2017, 1-2. Online. https://doi.org/10.1136/bmj.k2017

McKeown, J., Clarke, A., Ingleton, C. and Repper, J. (2010) 'Actively involving people with dementia in qualitative research'. Journal of Clinical Nursing, 19 (13-14), 1935-43. Online. https://doi.org/10.1111/j.1365-2702.2009.03136.x

Powell, M.A. and Smith, A.B. (2009) 'Children's participation rights in research'. Childhood, 16 (1), 124-42. Online. https://doi.org/10.1177/0907568208101694

Ritchie, J. and Spencer, L. (1994) 'Qualitative data analysis for applied policy research'. In Bryman, A and Burgess, R.G. (eds) Analyzing Qualitative Data. London: Routledge, 173-94.

Robson, P., Sampson, A., Dime, N., Hernandez, L. and Litherland, R. (2008) Seldom Heard: Developing inclusive participation in social care (Adults' Services Position Paper 10). London: Social Care Institute for Excellence.

Rojas, N.L., Sherrit, L., Harris, S. and Knight, J.R. (2008) 'The role of parental consent in adolescent substance use research'. Journal of Adolescent Health, 42 (2), 192-7. Online. https://doi.org/10.1016/j.jadohealth.2007.07.011

Rooney, L.K., Bhopal, R., Halani, L., Levy, M.L., Partridge, M.R., Netuveli, G., Car, J., Griffiths, C., Atkinson, J., Lindsay, G. and Sheikh, A. (2011) 'Promoting recruitment of minority ethnic groups into research: Qualitative study exploring the views of South Asian people with asthma'. Journal of Public Health, 33 (4), 604-15. Online. https://doi.org/10.1093/pubmed/fdq100

Rugkåsa, J. and Canvin, K. (2011) 'Researching mental health in minority ethnic communities: Reflections on recruitment'. Qualitative Health Research, 21 (1), 132-43. Online. https://doi.org/10.1177/1049732310379115

Sanci, L.A., Sawyer, S.M., Weller, P.J., Bond, L.M. and Patton, G.C. (2004) 'Youth health research ethics: Time for a mature-minor clause?'. Medical Journal of Australia, 180 (7), 336-8. Online. https://doi.org/10.5694/j.1326-5377.2004.tb05969.x 
Sheikh, A., Halani, L., Bhopal, R., Netuveli, G., Partridge, M.R., Car, J., Griffiths, C. and Levy, M. (2009) 'Facilitating the recruitment of minority ethnic people into research: Qualitative case study of South Asians and asthma'. PLoS Medicine, 6 (10), Article e1000148, 1-11. Online. https://doi.org/10.1371/journal.pmed.1000148

Smart, A. and Harrison, E. (2017) 'The under-representation of minority ethnic groups in UK medical research'. Ethnicity and Health, 22 (1), 65-82. Online. https://doi.org/10.1080/13557858.2016.118 2126

Smith, Y.R., Johnson, A.M., Newman, L.A., Greene, A., Johnson, T.R.B. and Rogers, J.L. (2007) 'Perceptions of clinical research participation among African American women'. Journal of Women's Health, 16 (3), 423-8. Online. https://doi.org/10.1089/jwh.2006.0124

Stake, R.E. (1995) The Art of Case Study Research. Thousand Oaks, CA: SAGE Publications.

Testa, A.C. and Coleman, L.M. (2006) 'Accessing research participants in schools: A case study of a UK adolescent sexual health survey'. Health Education Research, 21 (4), 518-26. Online. https://doi.org/10.1093/her/cyh078

Thompson, T.L. (1984) 'A comparison of methods of increasing parental consent rates in social research'. Public Opinion Quarterly, 48 (4), 779-87. Online. https://doi.org/10.1086/268883

Toledano, M.B., Mutz, J., Röösli, M., Thomas, M.S.C., Dumontheil, I. and Elliott, P. (2019) 'Cohort profile: The Study of Cognition, Adolescents and Mobile Phones (SCAMP)'. International Journal of Epidemiology, 48 (1), 25-6l. Online. https://doi.org/10.1093/ije/dyy192

UK Parliament (2005) Data Protection Act 1998: Chapter 29. 9th impression. Norwich: The Stationery Office.

Unger, J.B., Gallaher, P., Palmer, P.H., Baezconde-Garbanati, L., Trinidad, D.R., Cen, S. and Anderson Johnson, C. (2004) 'No news is bad news: Characteristics of adolescents who provide neither parental consent nor refusal for participation in school-based survey research'. Evaluation Review, 28 (1), 52-63. Online. https://doi.org/10.1177/0193841X03254421

Vickers, T., Craig, G. and Atkin, K. (2012) Research with Black and Minority Ethnic People Using Social Care Services (SSCR Methods Review 11). London: NIHR School for Social Care Research.

Wendler, D., Kington, R., Madans, J., Van Wye, G., Christ-Schmidt, H., Pratt, L.A., Brawley, O.W., Gross, C.P. and Emanuel, E. (2006) 'Are racial and ethnic minorities less willing to participate in health research?'. PLoS Medicine, 3 (2), Article e19, 201-10. Online. https://doi.org/10.1371/ journal.pmed.0030019

Woodall, A., Morgan, C., Sloan, C. and Howard, L. (2010) 'Barriers to participation in mental health research: Are there specific gender, ethnicity and age related barriers?'. BMC Psychiatry, 10, Article 103, 1-10. Online. https://doi.org/10.1186/1471-244X-10-103 